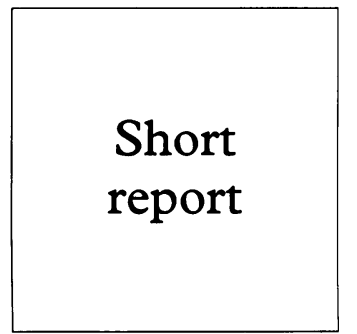

\title{
Genital colonisation and infection with candida in heterosexual and homosexual males
}

\author{
L M David, M Walzman, S Rajamanoharan
}

Objectives: To determine the penile, perianal, and oropharyngeal candidal colonisation rates among homosexual and heterosexual males attending an STD clinic. To determine the prevalence of balanitis and candidal balanitis in the two groups.

Subjects: 252 heterosexual and 210 homosexual male patients attending consecutively the STD clinic in Coventry, England.

Design: A prospective study recording sexual behaviour, relevant history, symptoms, and examination. Specimens for candida culture were collected from the glans penis, perianal area, and oropharynx.

Results: Among the 462 men studied, penile, perianal, and oropharyngeal colonisation rates were $74(16 \%), 70(15 \%)$, and $116(25 \%)$ respectively. On examination, $47(10 \%)$ were found to have balanitis. Of the 74 patients with penile colonisation, $26(37 \%)$ were symptomatic and 20 (27\%) had balanitis. The 223 heterosexual and the 196 homosexual males who had sexual intercourse within 3 months had comparable colonisation rates of candida on the penis, perianal area, and oropharynx. Balanitis was seen in 31 heterosexuals (14\%) and candidal balanitis in 16 or (7\%); the incidence was significantly less in homosexuals where balanitis was seen in $12(6 \%)$ and candidal balanitis in four (2\%).

Conclusions: Itching or burning sensations after sex were the most common symptoms associated with penile colonisation with candida and were present in more than one third. Candidal balanitis was commoner in those who had vaginal than those who had anal intercourse within 3 months.

(Genitourin Med 1997;73:394-396)

Keywords: candidiasis; balanitis; heterosexuality; homosexuality; men

\section{Introduction}

In the heterosexual population sexual transmission is a possible source of genital candidiasis. Higher rates of genital colonisation (same candida species) have been documented in sexual partners of those with genital candidiasis than those without genital candidiasis. ${ }^{12}$ Thin et al suggested that genital candidiasis is sexually acquired in $39 \%$ of women and $29 \%$ of heterosexual men attending an STD clinic. ${ }^{3}$

The intestinal tract has been implicated as the source of vaginal candidiasis in females. Both Miles et $\mathrm{al}^{4}$ and Hilton and Warnock ${ }^{5}$ isolated candida from the anorectum in significantly more patients with vulvovaginal candidiasis than those without.

If candidiasis can be sexually acquired, homosexual males may acquire infection from the gastrointestinal tract of their partners. This study compares the prevalence of symptomatic and asymptomatic penile candidiasis in homosexual and heterosexual males attending an STD clinic.

Department of Genitourinary Medicine, Coventry and Warwickshire Hospital L M David

$M$ Walzman

S Rajamanoharan

Correspondence to:

Dr L M David, Whittall Street Clinic, Steelhouse Lane, Birmingham $\mathrm{B} 46 \mathrm{NH}$. Accepted for publication 28 May 1997 were excluded. Patients who had taken antibiotics or antifungal therapy within 6 weeks before enrolment were excluded as were diabetic and immunocompromised patients.

Details of clinical presentation, sexual behaviour, relevant history, and examination were recorded. To maintain the consistency of the clinical diagnosis of balanitis, the presence of inflammation on the glans penis, one doctor examined all the patients. Candidal balanitis was diagnosed when patients with penile inflammation had a positive penile candida culture and responded by disappearance of the balanitis within 2 weeks of applying clotrimazole cream. To analyse the differences between heterosexuals and homosexuals, only $\tilde{\omega}^{N}$ those who had sexual intercourse within 3 ? months were included.

Specimens for candida culture were collected, using sterile cotton wool tipped swabs moistened with saline, from glans penis, perianal area, and oropharynx. Specimens were inoculated immediately on Sabouraud's medium and incubated within 3 hours at $37^{\circ} \mathrm{C}$ for 48 hours. For identification of candida, a germ tube test was used.

EPI INFO software was used for data entry and statistical analysis. The Mann-Whitney test was used to compare the mean age and number of partners between groups. The $95 \%$ confidence limits for odds ratio were calculated using Cornfield's approximation and exact confidence limits when indicated. 
Table 1 Demographic, cultural, and clinical differences between patients with and without candidal colonisation of the penis

\begin{tabular}{|c|c|c|c|c|}
\hline & \multicolumn{2}{|l|}{ Penile cultures } & \multirow[b]{2}{*}{ OR } & \multirow[b]{2}{*}{$(95 \% C L) t$} \\
\hline & Positive $(n=74)$ & Negative $(n=388)$ & & \\
\hline Mean age (range) & $30(17-50)$ & $31(16-71)^{\star}$ & & \\
\hline White & $68(92 \%)$ & $353(91 \%)$ & $1 \cdot 12$ & $(0 \cdot 44,3 \cdot 40)$ \\
\hline \multicolumn{5}{|l|}{ Sexual behaviour (previous 3 months) } \\
\hline $\begin{array}{l}\text { Sexual intercourse } \\
\text { Mean number of sexual partners (range) }\end{array}$ & $\begin{array}{l}70(95 \%) \\
1.7(0-8)\end{array}$ & $\begin{array}{l}349(90 \%) \\
1.6(0-10) \star \star\end{array}$ & 0.51 & $(0 \cdot 13,1 \cdot 49)$ \\
\hline Persistent use of condom & $18(24 \%)$ & $103(27 \%)$ & 0.89 & $(0.48,1.64)$ \\
\hline Circumcised & $6(8 \%)$ & $30(8 \%)$ & 1.05 & $(0 \cdot 35,2 \cdot 70)$ \\
\hline \multicolumn{5}{|l|}{ Candidal colonisation } \\
\hline Oropharynx & $17(23 \%)$ & $99(25 \cdot 5 \%)$ & $0 \cdot 87$ & $(0.46,1.62)$ \\
\hline Perianal & $17(23 \%)$ & $53(14 \%)$ & 1.89 & $(0.97,3.62)$ \\
\hline $\begin{array}{l}\text { Genital candidiasis within } 4 \text { weeks in partners } \\
\text { Relevant symptoms }\end{array}$ & $5(7 \%)$ & $8(2 \%)$ & $3 \cdot 44$ & $(0 \cdot 86,12 \cdot 30)$ \\
\hline $\begin{array}{l}\text { Penile redness, spots, or irritation } \\
\text { Penile itching or burning sensation after sex }\end{array}$ & $19(26 \%)$ & $\begin{array}{l}43(11 \%) \\
45(12 \%)\end{array}$ & $\begin{array}{l}2 \cdot 77 \\
4 \cdot 13\end{array}$ & $(1 \cdot 44,5 \cdot 31) \ddagger$ \\
\hline Balanitis: clinical diagnosis & $20(27 \%)$ & $27(7 \%)$ & 4.95 & $(2 \cdot 47,9 \cdot 90) \ddagger$ \\
\hline
\end{tabular}

†OR (95\% CL), odds ratio (95\% confidence limit). ¥Significant difference.

${ }^{\star} \mathrm{p}=0.62 .{ }^{\star \star} \mathrm{p}=0.28$.

Table 2 Candidal colonisation, balanitis, and history from heterosexual and homosexual males who had sexual intercourse within 3 months

\begin{tabular}{|c|c|c|c|c|}
\hline & $\begin{array}{l}\text { Heterosexual } \\
(n=223)\end{array}$ & $\begin{array}{l}\text { Homosexual } \\
(n=196)\end{array}$ & $O R$ & $(95 \% C L)^{*}$ \\
\hline \multicolumn{5}{|l|}{ Candidal colonisation } \\
\hline $\begin{array}{l}\quad \begin{array}{l}\text { including balanitis } \\
\text { excluding balanitis }\end{array} \\
\text { Perianal } \\
\text { Oropharngeal } \\
\text { Clinically diaonosed }\end{array}$ & $\begin{array}{l}44(20 \%) \\
28(15 \%) \\
32(14 \%) \\
55(25 \%)\end{array}$ & $\begin{array}{l}26(13 \%) \\
22(12 \%) \\
36(18 \%) \\
49(25 \%)\end{array}$ & $\begin{array}{l}1 \cdot 61 \\
1 \cdot 14 \\
0 \cdot 74 \\
0.98\end{array}$ & $\begin{array}{l}(0.92,2.82) \\
(0.60,2.14) \\
(0.43,1.29) \\
(0.62,1.57)\end{array}$ \\
\hline $\begin{array}{l}\text { Clinically diagnosed } \\
\text { Balanitis }\end{array}$ & $31(14 \%)$ & $12(6 \%)$ & $2 \cdot 48$ & $(1 \cdot 18,5 \cdot 28) \dagger$ \\
\hline Candidal balanitis & $16(7 \%)$ & $4(2 \%)$ & 3.71 & $(1.17,15.48) \dagger$ \\
\hline $\begin{array}{l}\text { Reported genital candidiasis in partners } \leqslant 4 \text { weeks } \\
\text { History }\end{array}$ & $11(5 \%)$ & $2(1 \%)$ & 5.03 & $(1 \cdot 08,47 \cdot 15) \dagger$ \\
\hline $\begin{array}{l}\text { Balanitis in patient } \\
\text { Balanitis in patient and genital candidiasis in partners }\end{array}$ & $\begin{array}{l}63(28 \%) \\
43(19 \%)\end{array}$ & $\begin{array}{l}24(12 \%) \\
4(2 \%)\end{array}$ & $\begin{array}{r}2 \cdot 82 \\
11 \cdot 47\end{array}$ & $\begin{array}{l}(1 \cdot 64,4 \cdot 90) \dagger \\
(4 \cdot 03,44 \cdot 67) \dagger\end{array}$ \\
\hline
\end{tabular}

*OR (95\% CL), odds ratio (95\% Confidence limit). †Significant difference.

\section{Results}

Of the 462 patients studied, candidal colonisation on the glans penis was found in $74(16 \%)$, on the perianal area in $70(15 \%)$, and in the oropharynx in $116(25 \%)$. Only $17(4 \%)$ had both penile and perianal colonisation.

Age, race, sexual behaviour, and being circumcised were comparable between patients with positive and negative penile candida culture (table 1). Colonisation rates of oropharynx and perianal area and reporting genital candidiasis in partners within 4 weeks among the two groups are documented in table 1. Relevant symptoms and balanitis were significantly associated with penile colonisation.

Of the total patients studied, $47(10 \%)$ had balanitis and $87(20 \%)$ reported previous balanitis. Previous balanitis was reported by 18 (38\%) patients with balanitis and 75 (18\%) patients without balanitis (odds ratio $2 \cdot 81$, $95 \%$ CL $1 \cdot 39,5 \cdot 55)$.

Of the 47 patients with balanitis, penile colonisation was found in $20(43 \%)$. All responded clinically to local treatment with clotrimazole. Among the 20 patients with candidal balanitis, nine $(45 \%)$ had perianal colonisation and five $(25 \%)$ reported previous balanitis compared with one (4\%), and 13 $(48 \%)$ in non-candidal balanitis patients.

Colonisation rates of penis, perianal area, and oropharynx were comparable between heterosexual and homosexual males (table 2). Balanitis, candidal balanitis, and reporting previous balanitis and previous balanitis with genital candidiasis in partners were significantly higher in heterosexual than homosexual men.

\section{Discussion}

In our study, the $16 \%$ colonisation rate of candida on the glans penis is similar to that found by others. ${ }^{6}$ More than one third of patients with penile colonisation were symptomatic. They either presented with penile redness, spots, and/or irritation or on direct questioning complained of itching or burning sensation after sexual intercourse.

The study suggested that balanitis is common among men attending STD clinics, and occurs most frequently in heterosexuals. A history of previous balanitis is more prevalent among those found to have balanitis, but is not particularly associated with candida infection.

It is generally accepted that candidal balanitis can be transmitted through sexual contacts. $^{7}$ In our study, four of the 16 heterosexuals with candidal balanitis reported recent vulvovaginal candidiasis in partners, and $43(19 \%)$ heterosexuals reported previous balanitis with concurrent vulvovaginal candidiasis in partners.

Candida is a normal commensal in the oral cavity and a quarter of our study population was found to carry candida in the oral cavity with no difference between heterosexual and homosexual males. We found a perianal colonisation rate of $15 \%$, this being lower than rectal colonisation rates of between 33\% and $41 \%$ in other studies. ${ }^{28}$ Vaginal colonisation rates are between $23 \%$ and $28 \% .{ }^{58}$ Despite this we found candidal balanitis to be three times commoner in heterosexual than homosexual males in our study. This may result from some homosexual males partici- 
pating in receptive anal sex only; alternatively vaginal intercourse may be more efficient in transmitting candida than anal intercourse or more virulent strains of candida may colonise the vagina.

Simultaneous treatment of the gastrointestinal tract and the genital tract does not cure chronic vulvovaginal candidiasis. ${ }^{9}{ }^{10}$ Our study raises doubts on the role of candida in the gastrointestinal tract of men as a significant cause of balanitis in homosexual males and whether it is commonly transmitted via anal intercourse.

A further understanding of the aetiology and pathogenesis of balanitis in general, and pathogenesis of genital candida infection in particular, might be achieved by studying in greater details the differences in balanitis in homosexual and heterosexual males.
We express our appreciation to Dr J Ross at Whittall Street clinic for reviewing the draft.

1 Sobel JD. Epidemiology and pathogensis of recurrent vulvovaginal candidiasis. Am f Obstet Gynecol 1985;152. 924-35.

2 Horowitz BJ, Edelstein SW, Lippman L. Sexual transmission of candida. Obstet Gynecol 1987;69:883-6.

3 Thin RN, Leighton M, Dixon MJ. How often is genital Thin RN, Leighton M, Dixon MJ. How often is genit

4 Miles MR, Olsen L, Rogers A. Recurrent vaginal candidiosis, importance of intestinal reservoir $¥ A M A 1977 ; 238$ : sis, impor

5 Hilton AL, Warnock DW. Vaginal candidiasis and the role of digestive tract as a source of infection. $\mathrm{Br} \mathcal{f}$ Obstet Gynaecol 1975;82:922.

6 Rodin P. Carriage of yeast on the penis. BMF 1976;1: 1123-4.

7 Edwards S. Balanitis and balanoposthitis: a review. Genitourin Med 1996;72:155-9.

8 Bertholf ME, Stafford MJ. Colonisation of Candida albicans in vagina, rectum and mouth. F Fam Pract 1983;16: in vagina,

9 Milne JD, Warnock DW. Effect of simultaneous oral and vaginal treatment on the rate of cure and relapse in vaginal candidosis. Br F Vener Dis 1979;55:362-5.

10 Vellupillai S, Thin RN. Treatment of vulvovaginal yeast infection with nystatin. Practitioner 1977;219:897-901. 